\title{
Escenarios de la patologización racial: la anomalía amerindia en una nación enferma*
}

\author{
Scenes of Racial Pathologization: The Amerindian Anomaly in a Diseased Nation
}

Carlos López Beltrán ${ }^{\dagger \ddagger}$

\begin{abstract}
Resumen
Como ha ocurrido en otros escenarios históricos, en esta época post-genómica se vive en México un nuevo episodio de patologización racializada de la población nacional. La idea tradicional de que los grupos mestizos de estas regiones heredaron fragilidades corporales y mentales de sus ancestros amerindios, que ha tenido versiones previas en escenarios teóricos cambiantes, se ha vuelto a articular, se ha vuelto a articular, esta vez afincada en "variantes genéticas amerindias" que supuestamente predisponen a enfermedades metabólicas a sus portadores, y que de ese modo explican las epidemias en curso. Este artículo recorre la historia de esos escenarios de patologización racial, e intenta mostrar la lógica distorsionada (ideologizada) en la que se mueve este nuevo y pernicioso ciclo de patologización racializada de la población mexicana.
\end{abstract}

Palabras clave: genómica racial - patologización - población mestiza - genética amerindia

\begin{abstract}
As in other historical scenes, in recent post-genomic times Mexico has witnessed an episode of racialized pathologization of its populations. The traditional idea that mestizo (racially admixed) groups of the region inherit their bodily and mental frailties from their Amerindian ancestors has had several previous incarnations in different and changing theoretical frames. It has now found a new version rooted in the supposed link between "Amerindian genetic variants" that allegedly predispose the bearers to metabolic diseases, and explain the ongoing epidemics. This paper summarizes the history of the scenes of racial pathologization and shows the ideologically distorted racialist logic within which this recent pathologization of Mexicans is taking place.
\end{abstract}

Keywords: racial genomics - pathologization - admixed populations - Amerindian genetics

\footnotetext{
* Recibido: 15 de Julio de 2016. Aceptado con revisiones: 25 de Diciembre de 2016.

+ Instituto de Investigaciones Filosóficas (IIF), Universidad Nacional Autónoma de México (UNAM). Para contactar al autor, por favor, escribir a: carloslopezbeltran@gmail.com.

\$El autor desea agradecer la colaboración de Vivette García Deister en los procesos de investigación e interpretación que respaldan este escrito. Agradece también apoyos económicos del programa PASPA-UNAM y Conacyt para una estancia sabática corta en Cambridge, UK, durante la cual se hizo parte de esta investigación en 2014.

Metatheoria 8(2)(2018): 181-193. ISSN 1853-2322.

(c) Editorial de la Universidad Nacional de Tres de Febrero. Publicado en la República Argentina.
} 
Uno de los tropos principales para la concepción de la población moderna de las Américas está centrado en la hibridación/la mezcla racial/el mestizaje. Como es sabido, esta figura de doble filo: el mestizo/el mestizaje, ha sido proyectada una y otra vez, insistentemente, bajo marcos ideológicos y científicos diferentes, sobre el cuerpo político americano.

El tropo que comúnmente acompañó al del mestizo/mestizaje fue el del cuerpo enfermo y defectuoso del aborigen amerindio, que vuelve a su vez enfermo al cuerpo de su producto hereditario: el mestizo.

La era genómica nos ha traído una nueva ola de patologización de los cuerpos mexicanos. En un artículo reciente, mi colega Vivette García Deister y yo exploramos los modelos en los que la genética humana (biomédica y forense) participa en la expansión contemporánea de una sensación generalizada de inquietud y fracaso de México como nación, y de los mexicanos como un colectivo humano (GarcíaDeister \& López-Beltrán 2015, Kempis 2013). Una vez más nos estamos concibiendo a nosotros mismos como una nación enferma y los científicos están participando, quizá inconscientemente, en ello.

Y digo "una vez más" porque esta ha sido una situación recurrente por varios siglos.

Dentro de su historia moderna, bajo casi cualquier situación política y "teórica”, casi todos los grupos étnicos mexicanos (utilizando un término anacrónico) han sido diagnosticados como físicamente deficientes y moralmente discapacitados (Althaus 2013). El marco Hipocrático-Galénico bajo el cual el supuesto sistema de castas colonial imaginó el cuerpo mestizo y sus desbalances, generó un esquema normativo hereditario complejo donde el blanqueamiento se obtenía de manera exitosa al diluir la sangre indígena (nativa), y sin tanto éxito cuando la sangre africana era la que se quería diluir (López-Beltrán 2007, 2008). La impureza, la mancha pre-racial, junto con los defectos morales y físicos, eran el supuesto objetivo de la purificación matrimonial.

A aquella primera "escena de la patologización" mexicana le siguió otra que se desarrolló durante el siglo XIX. El deseo postcolonial de crear una nación moderna con las hilachas raciales de los cuerpos indios, españoles, africanos y mestizos, dio lugar a un escenario conflictivo donde el cuerpo unificado ideal (biológico y político) de la nación estaba bajo disputa.

La noción endurecida de herencia biológica que adoptaron los racialistas radicales europeos (a menudo poligenistas) condenaba el mestizaje. Ante ella hubo siempre resistencia en México, ya se tendía a ver el mestizaje como un resultado inevitable de la promiscuidad del periodo colonial, y a entender su continuación, de una manera u otra, como la mejor salida (Tenorio 2006, 2009). El mantenimiento de un proceso de blanqueamiento y dilución (a través de una inmigración europea continua) que defendía la clase alta conservadora mexicana, encontró resistencia de parte del grupo liberal, entre quienes había muchos mestizos de clase media, que preferían un mestizaje sin inmigración, que tenía como objetivo asimilar a la aún enorme proporción indígena de la población en una ciudadanía morena homogénea. Ello propició en México la adopción de puntos de vista más "blandos" acerca de la transmisión hereditaria, que aceptaban la posibilidad de rápidas mejoras intra e intergeneracionales a través de la educación, la nutrición adecuada y actividad física, para volver factible tal ambición colectiva. Como contraste, el refuerzo de una renovada escena racial patologizante se dio como reacción de la élite hispanófila ante esta naciente utopía mestiza. Como Martin Stabb ha descrito, el tropo de la nación como un cuerpo enfermo centró la actividad de una serie de "diagnosticadores" que utilizaron la noción de la falta de armonía racial del mestizo, fincada en el aporte patológico del indio (Stabb 1967).

Dijimos que la vieja metáfora que representa a las naciones como si fueran un cuerpo lleva de manera natural a la noción de nación enferma. Al ser un recurso retórico eficaz, el tropo de un cuerpo nacional enfermo continuó migrando a través de las décadas, colonizando varios marcos teóricos médicos e higienistas. En el espacio político de las colonias españolas en América, todos los grupos étnicos sufrieron bajo la mirada patologizadora. Primero estuvieron los grupos amerindios originarios, 
luego los criollos europeos y africanos, y finalmente los mestizos producto de tres siglos de interacciones sociales coloniales. Todos ellos fueron representados como enfermos, tanto de manera física como moral (Gerbi 1955). Las combinaciones de influencias hereditarias astronómicas, climáticas, nutricionales, de temperamento y similares, han sido desplegadas en diferentes periodos para apuntalar las patologizaciones resistentes de los cuerpos políticos latinoamericanos (Earle 2012, Cañizares-Esguerra 1999, López-Beltrán 2007). Adoptando posturas antagónicas desde miradores situados afuera o adentro de las Américas, los teóricos llegan al diagnóstico de la enfermedad, y a adoptar la retórica de la necesidad de curar el defecto de origen. Al igual que otros países de la región, México llegó a los principios del siglo XIX a su independencia política en mal estado. Se le juzgaba por las élites locales o extranjeras, como un cuerpo nacional enfermo, inestable, desequilibrado y deteriorado. Para poder aspirar a la civilización y a la soberanía necesitaba curarse.

Varios ensayistas latinoamericanos de finales del siglo XIX y principios del XX, quienes emprendieron la tarea de pensar en la región como una alternativa histórica real dentro de la civilización occidental, fueron descritos, como ya dije, como "diagnosticadores" de un continente enfermo. Intelectuales influyentes, como el positivista mexicano Francisco Bulnes (1847-1924), el sociólogo y abogado argentino Carlos Octavio Bunge (1875-1918), el abogado y brevemente presidente peruano Francisco García Calderón (1834-1905), y su compatriota el antropólogo José María Arguedas (1911-1969), nos dieron retratos de sus sociedades debilitadas y enfermas, y consideraron su deber presentar el diagnóstico y explicar la cura (Stabb 1967). El origen del problema era el terrible error de haber permitido el mestizaje de demasiados elementos raciales dentro de América por demasiadas generaciones, y en algún punto solamente las soluciones radicales podrían servir. Resume Stabb el trabajo de algunos de estos diagnosticadores.

A la pregunta “ipor qué estamos enfermos?", Bunge, Arguedas, García Calderón e Ingenieros responden en términos tajantes. Estamos enfermos por culpa de nuestra mala sangre, por la preponderancia en nosotros de las razas "inferiores" no europeas. Si se busca una cura para los males del continente, estos escritores recetan el mismo remedio: la inmigración europea, la asimilación prudente de las razas de color, su educación y su "uso" dentro de los límites restringidos de sus habilidades (Stabb 1967).

En México, destacó Francisco Bulnes entre quienes articularon una visión científica y biológica de los problemas políticos del país hacia finales del siglo XIX. Bulnes adoptó una visión anti-reduccionista de la determinación de lo moral por lo físico y desarrolló una teoría nutricional de la diferenciación racial y el mestizaje. Por su alimentación básica, los indios mexicanos eran para él la raza del maíz, y su constitución era defectuosa por la mala calidad de ese grano, mientras que nuestros ancestros españoles y nuestras élites blancas pertenecían a la raza del trigo, que era más perfecta debido a las bondades de ese cereal. Dentro del cuerpo del mestizo había, así, un conflicto entre la influencia de ambos alimentos (uno primitivo, el otro civilizado) que nunca lograría llegar a una solución armoniosa. Pan en vez de tortilla, cerveza en vez de pulque; ese era el tipo de cambios que recetaba Bulnes, junto con la inmigración europea masiva. La herencia suave (llamada lamarckismo por los historiadores del darwinismo) haría lo demás a lo largo de unas cuantas generaciones. Los defectos físicos del indio poco a poco se convertirían en algo del pasado, al igual que su patología moral.

Con los desacomodos profundos de la Revolución Mexicana (1910-1927) emergió una nueva escena de patologización racial. En ese periodo de reorganización del Estado, diversos profesionistas (i.e. antropólogos, científicos sociales y médicos) competían por espacios y cargos en las dependencias de gobierno nacientes, ligadas a la gestión poblacional. Varios proyectos alternativos convivieron, con distintas propuestas sobre qué hacer con los indígenas y con la mayoría mestiza, tratando de homogeneizar y de mitigar el resentimiento racial. Proyectos alternativos indigenistas, eugenistas y socialistas compitieron por el control de las políticas de estado.

La antropología y la biomedicina racializadas (con el mestizo como punto de apoyo) desplegaron sus proyectos y produjeron una serie de tensiones disciplinarias y políticas. Algunas de esas tensiones 
brotaban de la necesidad de adaptar o desafiar las teorías y prácticas biológicas, biomédicas y antropológicas importadas del norte, al modularse su pertinencia con conflictos e intereses locales, y adaptarse a los objetivos biopolíticos y a las aspiraciones institucionales o personales de los diversos actores. Otras tensiones tuvieron que ver con conflictos ideológicos o políticos (fincados en las diferencias de clase) sobre cómo valorar la historia demográfica del país (con su diversidad de cuerpos y de grupos étnicos y sociales) y sobre qué clase de intervenciones verticales debe realizar el Estado en la población a través de las instituciones legales, educativas y médicas, con el fin de corregir el presente y dar forma a la futura deseable configuración demográfica del país (Gall 2013, López-Beltrán \& GarcíaDeister, en prensa).

Podemos enlistar a los principales grupos de actores disciplinares de las ciencias racializadas en México durante el siglo XX: Mencionaremos primero a los médicos, quienes se reúnen en instituciones de salud pública alrededor de proyectos higienistas y hereditaristas, eugenésicos. Este gremio introdujo políticas eugenésicas con relativo éxito. Importadas y adaptadas del movimiento eugenésico internacional, introdujeron programas de salud social pública y promovió el empoderamiento de los médicos, sobre temas sociales y legales, como el matrimonio, la planeación familiar, la puericultura y el deporte. Su influencia menguó hacia mediados del siglo XX al mismo tiempo que la eugenesia y los proyectos similares cayeron en relativo desprestigio (Saade 2009).

El segundo grupo que mencionaré es el de los abogados, criminólogos, psicólogos, sociólogos y maestros. Estos científicos sociales lucharon por ocupar un papel central en el esfuerzo de construcción del Estado-nación post-revolucionario, tratando de hacer de sus conocimientos herramientas de Estado para los esfuerzos legales, demográficos y educativos de la nación. El cambio radical de foco de las políticas poblacionales que se dio a lo largo del siglo se dirigió a integrar a los grupos indígenas para robustecer una población mexicana mestiza sana y homogénea. Muchos de estos profesionales ocuparon puestos tanto en la academia como en oficinas gubernamentales. Este grupo ecléctico fue, por ejemplo, responsable de incorporar la tradición biotipológica italiana para diagnosticar las cualidades físicas y morales de los indígenas y de los grupos proletarios. Estos grupos también perdieron presencia e influencia hacia la segunda mitad del siglo (Urías Horcasitas 2007b, Stern 2003).

El tercer grupo al que me refiero, lo formaron antropólogos sociales y físicos que se aglutinaron en el movimiento indigenista y que ocuparon un papel central en la creación y desarrollo de las soluciones estatales a los problemas políticos, económicos y culturales planteados por la tenaz supervivencia de los grupos indígenas. Por varias décadas el Indigenismo tuvo un papel destacado tanto en proyectos nacionales como regionales, los cuales generaron varias instituciones indigenistas. Las labores de este grupo allanaron el camino de la racialización o, mejor dicho, cripto-racialización de los cuerpos y mentes mexicanos, transitando con las décadas hacia el culturalismo (Knight 1990). Los indigenistas terminaron finalmente recibiendo el golpe de las críticas marxistas de los años sesenta, y multiculturalistas de los años noventa del siglo XX, que terminaron arrasando sus vetustos marcos conceptuales y políticos básicos.

El cuarto grupo corresponde a los que llegaron más tarde: los genetistas de poblaciones humanas y los científicos biomédicos entrenados en la biología molecular, que junto con algunos antropólogos físicos, "modernizaron" el acercamiento analítico a la diversidad biológica humana en México al incorporar un amplio rango de técnicas y marcadores biológicos (fenotípicos, genéticos y moleculares) para describir lo racial y así poder evaluar las características de la variación biológica de las poblaciones regionales según su historia demográfica. Activos durante la segunda mitad del siglo XX, este grupo encontró en el avance tecnológico modos de buscar evidencia molecular (cuantificable) del mestizaje. Emprendieron esta tarea haciendo confluir investigaciones indigenistas y biomédicas (Suárez \& Barahona 2011). Los resultados de este grupo (en su mayoría biomédicos) pueden verse hoy como un claro antecedente para los conocidos desarrollos en racialización de la ciencia mexicana de principios del siglo XXI, como es el Proyecto del Genoma Mexicano de INMEGEN (López Beltrán 2011). 
En las décadas iniciales de la post-revolución se desarrollaron dos ramas principales del pensamiento racialista ligadas a las escuelas indigenista y eugenista. La primera se inició con los esfuerzos teóricos e institucionales de Manuel Gamio, estudiante de Franz Boas, que a partir de los años veinte desarrolló una versión mexicana de culturalismo antropológico que tenía como eje "el problema del indio" (Gamio 1916). Una escuela que tuvo un recorrido de 50 años en el México postrevolucionario (de 1920 a 1970 aproximadamente). La otra rama fue la eugenesia y tuvo una vida más corta. En ella se congregaron las posiciones más radicalmente racistas, en las que se perpetuaba la práctica añosa de culpar y patologizar al indio (Urías Horcasitas 2007b). Concentradas dentro de grupos profesionales de médicos y maestros hispanófilos y de visiones conservadoras, las ideas eugenésicas tuvieron un peso importante. Reunidos, entre otros lugares, dentro de la Sociedad de Eugenesia, su influencia se disipó después de 1950 (Saade 2009).

La tensión social y política hacia la que se orientan los proyectos de eugenesia y los indigenistas del siglo XX puede también ser descrita en términos de visiones contrastantes planteadas por dos mestizofilias alternativas. Una, la eugenesia conservadora hispánica y latina, cuyo objetivo era la homogeneización blanqueadora de la población mexicana, que pone como meta un mestizo de piel clara, europeizado que pudiera, a través de políticas de eugenesia y migración, diluir los elementos indios y africanos, y reforzar el dominio de las virtudes hispánicas (latinas). La otra, la visión del futuro de la población mexicana mestiza que estaba orientada a revalorar lo indígena, y que fue adoptada básicamente por los indigenistas. Ésta tenía como objetivo incorporar a los indígenas al cuerpo de la población mestiza a través de la aculturación, de la transformación económica y el entrecruzamiento biológico, de manera compasiva y ordenada, conservando valores positivos culturales y morales latentes o patentes en las raíces tradicionales.

La incorporación de ambos tipos de profesionales y científicos en distintos espacios del proyecto sexenal del presidente Lázaro Cárdenas (1934-1940) quien apoyó de manera material e institucional a ambos tipos de proyectos biopolíticos, tanto el eugenista como el indigenista. Servidores públicos de la Secretaría de Salud Pública cardenista canalizaron los esfuerzos de médicos, psiquiatras, sociólogos, criminólogos y abogados, en dirección eugenésica en busca del "Hombre (mestizo) Nuevo" (Urías Horcasitas 2007a), mientras que en el "Departamento de Asuntos Indígenas" y el "Departamento Demográfico" de la Secretaría de Gobernación se echó mano de los esfuerzos de demógrafos y antropólogos alineados con el movimiento indigenista. (Knight 1990). El Instituto de Investigaciones Sociales en la UNAM fue otro lugar donde los científicos idearon y desarrollaron proyectos de intervención biopolítica en la población.

Hacia el final del sexenio de Cárdenas, ambos proyectos prosperaban. Historiadores recientes han demostrado cómo la adaptación a las circunstancias de México de la biotipología estilo italiana era una estrategia común que permitía a los poblacionistas mexicanos invalidar la racialización más nociva de indígenas y mestizos, sin abandonar el punto de vista clasificatorio y jerárquico (en términos de civilización y de lo físico) de los grupos (o tipos) humanos (Stern 2000). Las conclusiones contrastantes sobre las políticas demográficas del periodo de dos académicas destacadas muestran de manera clara la tensión entre las dos mestizofilias a las que me refiero.

Según Alexandra Minna Stern, las élites mexicanas -ya sean médicos, demógrafos, antropólogos o sociólogos- estuvieron consistentemente restringidas por las contradicciones de buscar la "verdad" y la objetividad en teorías y prácticas disciplinarias que idealizaban un tipo humano que, básicamente, y a veces de manera invisible, fuera urbano, blanco, letrado y de clase media (Stern 2000).

Esta mestizofilia orientada hacia el blanqueamiento dominó la eugenesia racialista mexicana. La otra conclusión contrastante se enfoca menos en las fantasías de las élites y más en los deseos del capitalismo liberal nacionalista. Se la debemos a Beatriz Urías Horcasitas.

Los diversos componentes del programa de "ingeniería social" posrevolucionario buscaron crear una nueva sociedad "regenerada" mental y físicamente, y conformada por un nuevo tipo de ciudadano: el "Hombre 
nuevo" [...] era racialmente un mestizo. Su perfil social combinaba rasgos del proletario obrero y campesino, y de la clase media. (Urías Horcasitas 2007a)

Estas dos conclusiones nos revelan la tensión que divide las principales iniciativas racialistas. Tanto Agustín Basave como Alan Knight han demostrado que el contraste entre la posición pro-indígena del Gamio tardío y la pro-hispanista de Vasconcelos claramente se anclan en narrativas de mestizofilias opuestas (Basave 1992, Knight 1990, Gall 2013, Turda \& Gillete 2014).

Es importante darse cuenta de que la mayoría de los pensadores racialistas mexicanos del siglo XX usaron nociones suaves (lamarckianas) de herencia, naturaleza y crianza, que se puede describir como una mezcla poco ortodoxa de explicaciones sociológicas, históricas y biológicas. Este tipo de esquema retrata el mestizaje entre españoles e indígenas no como algo que causa necesariamente un trastorno biológico profundo a nivel fisiológico, ni como algo determinado por completo por la genética. Un conjunto más suave y variado de causas y eventos es lo que articula entonces la noción de mestizaje, dentro de la cual las inercias de diversas influencias holísticas se podían balancear política o biológicamente por medio de ajustes ambientales y culturales. La transición de indígena a mestizo (hacia el mejor mestizo posible dadas las circunstancias) no se concebía como una secuencia puramente biológica, sino mucho más importantemente como una determinada por influencias culturales, económicas y morales.

Este tipo de marcos explicativos ha sido descrito tradicionalmente como una apropiación latinoamericana del marco conceptual lamarckiano o neo-lamarckiano. La principal responsable de ese uso es Nancy Stepan. A su vez, la historiadora de la ciencia Alexandra Minna Stern adoptó esa descripción de las posturas teóricas de los científicos racialistas mexicanos del siglo XX, insistiendo que estaban divididos entre el mendelismo y el neolamarckismo. No me parece sin embargo un recurso historiográfico adecuado; en mi opinión, no se obtiene mucha claridad al enmarcar así las posturas y tensiones entre los cientificos y médicos racialistas mexicanos. Estas categorías historiográficas fueron llevadas al análisis del movimiento de eugenesia latinoamericano en los ochenta, trayéndolos de las prácticas de los historiadores de la biología nórdica centrados en Darwin y Mendel, pero se desenfocan dramáticamente al proyectarse sobre los médicos de México y Latinoamérica (Stepan 1991, Stern 2004). Concebida para enfocarse en las incompatibilidades y contradicciones lógicas y fisiológicas entre dos modelos contrastantes de la transmisión hereditaria de características biológicas, la dicotomía, para los historiadores y filósofos de la ciencia, se enfocaba en mostrar la naturaleza progresiva o regresiva de tales programas de investigación (v.gr. lisenkoismo vs. morganismo). Raramente estuvo la transmisión particular weissmaniana contra la herencia de las características adquiridas en la mente de los científicos racialistas latinoamericanos a lo largo del siglo XX, y no a menudo aparecen en sus escritos los nombres de las teorías de Mendel y Lamarck o de sus seguidores teóricos. Lecturas atentas muestran que fue más bien de autores como Spencer, Haeckel, Delage, Le Bon, y otros similares, de los que la mayoría de los pensadores en esta área cultural adquirieron sus puntos de vista sobre la transmisión hereditaria. La herencia humana a menudo es vista por ello como un proceso complejo, de naturaleza holística y contradictoria, en el que se combinan atavismos (influencias ancestrales retrógradas) y capacidades de creación innovadora (o adaptación) de los organismos. La noción compartida por muchos sabios de la región era que la evidencia empírica, médica y antropológica acumulada que se inclinaba hacia explicaciones holistas no necesariamente lamarckianas.

Los cuatro grupos profesionales descritos tuvieron, de un modo u otro, como objeto de estudio los cuerpos indios y mestizos. En sus manos sufrieron cambios de acuerdo con las agendas disciplinarias y las prácticas científicas. El indio y el mestizo se consolidaron como objetos de la ciencia. La obsesión biotipológica por caracterizar a la población del país dio lugar a un eje analítico indio/mestizo. La antropología mexicana se enfocó en las particularidades de los cuerpos indios y sus características étnicas, mientras que el mestizo generó un problema para el esencialismo y el pensamiento tipológico. Considerados física y culturalmente como seres híbridos, intermedios, los mestizos carecieron por mucho tiempo de particularidad, color local y especificidad. Su antropometría resultaba también 
menos interesante y posiblemente menos atractiva dentro de la ciencia. Esta situación cambió cuando los antropólogos y los médicos mexicanos voltearon la mirada a los nuevos grupos de población mayoritaria identificados en el censo de 1940. Ese impulso además coincidió con el esfuerzo internacional de lavarle la cara a las ciencias racialistas, con las declaraciones de la UNESCO a partir de 1950, que intentaron eliminar al racismo de las observaciones científicas de la diversidad humana, y de rechazar visiones denigrantes del mestizaje entre grupos. También influyó el que las nuevas técnicas moleculares para llegar al detalle de la variación poblacional, facilitó la descripción de los cuerpos indios y mestizos en términos de mezcla o combinación molecular (Salzano \& Bortolini 1999).

Una característica importante de las prácticas de bioantropología de mediados del siglo XX dentro de México fue la bastante paradójica preservación y refuerzo del hiato o distancia biológica y cultural entre los indios y el resto de los mexicanos mestizos. Al mismo tiempo, tanto el acercamiento indigenista como el eugenésico apuntaban hacia transformar y aculturar a los grupos indígenas para poder disolver "el problema del indio". Mucha investigación y propaganda se dirigió a ubicar, reconocer y describir grupos indígenas esparcidos a lo largo de toda la geografía del país. Una mezcla de asombro, orgullo y temor en cuanto a la gran diversidad y riqueza de diferencias culturales y biotipológicas aun presente dentro de México potenciaron los esfuerzos de antropólogos, lingüistas y médicos (Lomnitz 2010). El indio continuó llevando la carga de la culpa por nuestro rezago, pero también aportaba posibles elementos redentores que proveían de ventajas comparativas en el mundo, si no físicas sí de culturales. La valoración de la contribución del indio a "nuestro mestizaje" fue mayor. El aspecto físico de la herencia indígena continuó estando bajo sospecha. Dejando de lado "ontologías" identitarias temperamentales y psicológicas por las cuales la élite intelectual mexicana del siglo XX (siguiendo la moda europea) sentían aprecio, la condición básicamente enferma (degenerada) de los cuerpos indígenas recibió varias reestructuraciones (Gómez \& Sánchez 2011).

Por otro lado, una serie de indagaciones sobe genética poblacional humana en México a mediados del siglo XX se centraron alrededor de las marcas genéticas raciales entre los indígenas (frecuentemente patologizadas), sus condiciones especiales y su influencia hereditaria en los cuerpos mestizos mexicanos (Lisker 1981).

Recientemente se ha enfatizado la relativa falsedad del relato mestizante, se le ha opuesto el hecho demográfico enfatizado por historiadores (Levin \& Navarrete 2007), que durante la mayor parte de la historia del país, el llamado proceso de mestizaje no ha estado movido por la proliferación de matrimonios entre personas de orígenes raciales diferentes, sino más bien por una intensa aculturación (o ladinización) de comunidades indígenas, en la cual un gran número de ellos fueron progresiva y masivamente recalificados como mestizos, mientras abandonaban las lenguas originarias y adoptaban el español, junto con otras características culturales occidentales. Así, muchos mexicanos se transformaron de indios en campesinos, o se convirtieron en trabajadores urbanos, nutriendo las filas de los ciudadanos mestizos desposeídos.

Cuando las herramientas técnicas para el análisis de la diversidad molecular estuvieron a mano, los genetistas mexicanos decidieron que a la investigación biomédica y antropológica de poblaciones locales le convenía asumir de entrada el carácter mestizo del mexicano típico, y crearon el concepto "población mestiza mexicana" para referirse a cualquier grupo no indígena que estuviera siendo investigado. Muy a menudo se trató de pacientes capturados bajo el paraguas de la del sistema de salud pública. La mayoría de los grupos de investigación en genética humana, que estaban ligados a alguna universidad pública, o al sistema nacional de salud, y brindaba una fuente generosa de pacientes "voluntarios" para la investigación genética. La presunción, soportada de modo inconsciente por una narrativa histórica oficial, era que todos los sujetos de investigación "capturados" con esa malla eran necesariamente mestizos. Y la única otredad contemplada por los investigadores era la indigenidad. Hacer genética del indio implicaba un muestreo especial que movilizaba las estructuras paternalistas hacia los grupos étnicos marginados y arrinconados geográficamente. La genética de los indígenas (al igual que otras investigaciones indigenistas) fue enmarcada en un pujante colonialismo interno, a 
partir de expediciones a regiones remotas, para las cuales los antropólogos oficiales controlaban el acceso, y se solía (y suele) utilizar campañas nacionales relacionadas con salud por el reclutamiento de muestras genéticas. Las preguntas de investigación estaban enmarcadas y moduladas a partir de las etiquetas étnicas (con base en los grupos indígenas reconocidos) y abordaban temas como las consecuencias de la endogamia, del aislamiento a largo plazo, o de la supuesta pureza genética amerindia y similares. Entre los hitos de la carrera del reconocido genetista Rubén Lisker destaca su búsqueda de marcas moleculares de la historia poblacional de grupos étnicos, cuidadosamente seleccionados y clasificados, a menudo usando mutaciones ligadas con enfermedades especiales que, además de tener importancia médica, se pueden usar por construir inferencias que podrían esclarecer el mestizaje histórico y el linaje (Lisker 1981).

En tiempos más recientes la población mexicana está siendo sometida una vez más a una fuerte mirada diagnóstica, con coloraturas y trasfondos raciales. Desde diferentes ventanas a México se le está representando (y valorando) una vez más como una nación patológica. Una de estas ventanas es la epidemia en curso de diabetes y obesidad. La asociación probabilística de estos padecimientos con variantes genéticas mexicanas (amerindias) particulares es un recurso habitual. El énfasis en buscar estos fenómenos se antoja un eco de lo que hicieron previos diagnosticadores de la élite criolla. La recirculación de una retórica nociva que delimita, enfatiza y particulariza las enfermedades del mexicano a partir de su ancestría amerindia parece tener el propósito de activar estrategias étnicas racializadas de remedio biopolítico.

El tropo de México como un país enfermo suele aparecer por todos lados en los últimos años. "México está enfermo de obesidad" declara un médico especialista al comentar sobre los millones afectados por esta enfermedad. Otro investigador concluye que la diabetes es la patología más desafiante económica y políticamente para el mexicano. Como hemos mostrado Vivette García Deister y yo, esta nueva patologización apuntalada por la genética ha sido tristemente acompañada por otra gran enfermedad nacional, la de la muerte y la violencia. Esta última también vinculada de modo complejo a la genética (García-Deister \& López -Beltrán 2017).

La creación en 2004 del Instituto Nacional de Medicina Genómica (INMEGEN) y su principal proyecto inicial, el Proyecto de la Diversidad del Genoma Mexicano, puede explicarse en parte por la alarma que las instituciones de salud nacional sentían en relación con la epidemiología de enfermedades metabólicas mencionada. Como en otros lugares, en México la medicina genómica prometió acercar en unos pocos años, la solución a esas enfermedades. Los políticos y el público en general estaban ciertamente impresionados por la retórica cientificista que apuntaba hacia nuestro muy especial (aunque un poco defectuoso) genoma nacional como el principal culpable, y hacia una farmacogenómica nacional como la herramienta principal (Jiménez Sánchez 2003, 2009). El proyecto, popularmente descrito como el Genoma del Mestizo Mexicano, se concentró en producir un "mapa" de los haplotipos más comunes en México, y evaluar los porcentajes de mezcla racial utilizando marcadores informativos de ancestría, y la estructura poblacional y las distancias genéticas entre los pobladores de diferentes regiones mexicanas (López-Beltrán 2011, Wade et al. 2014).

Un aspecto esencial de las estrategias públicas de INMEGEN en su primer periodo fue insistir que el enemigo a futuro del mestizo mexicano (en cuestión de mala salud y mortalidad) ya había mostrado sus terribles dientes de factura genética. Dado que, según ellos, las enfermedades asociadas a la pobreza y el subdesarrollo ya estaban cediendo demográficamente el paso a las complejas y sofisticadas enfermedades metabólicas de los países ricos, éstas requieren aparatos biotecnologicos también sofisticados para su contención (Jimenez Sánchez, Soberón \& Frenk 2010, Frenk 2001). La principal carga patológica estaba asociada al componente genético amerindio dentro del cuerpo del mestizo mexicano. Explicaciones llamativas de corte evolucionista (como la hipótesis del gen ahorrador) fueron por ejemplo reclutadas para reforzar la idea de una herencia amerindia ancestral, que es responsable de la predisposición de un enfermar subyacente en cada mestizo. El nivel de riesgo (predisposición a enfermedades genéticas) del mexicano es tan alto que vivimos al borde de una línea muy delgada, la 
cual puede cruzarse fácilmente al adoptar malos hábitos, y de ese modo cumplir la profecía condenatoria de nuestros genes amerindios ancestrales. Las campañas de salud pública provenientes del gobierno reflejaron esa visión (Wade et al. 2014).

Inicialmente, los genetistas mexicanos del inicio del nuevo milenio, a partir de los problemas de otras regiones, estaban renuentes a hacer genética poblacional indígena. De ahí que la figura unificadora del mestizo haya sido la elección natural para la genómica nacional. INMEGEN intentó prescindir de muestrear grupos indígenas, pero la estructura básica de su marco inferencial de mestizaje les exigió involucrarse con la indigenidad. Según Vivette García Deister:

Los investigadores concluyeron que fue la contribución del linaje amerindio al mestizo mexicano, lo que los hizo genéticamente singulares. Pero esta inferencia también incorporó una dimensión patológica, pues la porción amerindia del genoma también se entendió como la portadora de la variante genética que hace a los mestizos susceptibles a la obesidad y a la diabetes. La implicación es que el legado que le dejó el indígena al mestizo, combinado con un entorno nutricional enormemente diferente a la dieta indígena original, es responsable hoy día de una crisis de salud pública (García-Deister 2014, p. 178).

INMEGEN y varios otros grupos de investigación mexicanos han estado insistentemente buscando cuáles son las variantes genéticas dentro de la población mexicana que se pueden asociar con las enfermedades metabólicas y complejas que nos amenazan. Hay mucho que decir a favor de las sofisticadas e ingeniosas estrategias de investigación que los genetistas biomédicos siguen para poder buscar y arrinconar todas las muchas variantes genéticas que, con diferentes niveles de intensidad, contribuyen genéticamente al riesgo de padecer esas enfermedades. Desafortunadamente hasta ahora solamente ha logrado explicar genéticamente menos de un 10\% de la incidencia de las condiciones más investigadas (v.gr. diabetes del tipo 2) (Tusié 2015, Gamboa et al. 2012). Mi interés no es poner en duda el objetivo básico de explorar las variantes en el genoma en busca de factores causales de riesgo, sino poner de realce la prolongación inercial que los grupos de investigación médica genómica en México han hecho de los mismos patrones paternalistas con los que tratan y califican a los grupos y poblaciones dependientes del sistema nacional de salud, o no, racializados irresponsablemente con un despliegue de etiquetas clasificatorias y actitudes prepotentes. Ya sean indígenas o mestizos, lo que percibimos es una confusión clasificatoria en las iniciativas científicas que reproducen los patrones de patologización racial que "culpan a los tlaxcaltecas" (utilizando el famoso título de Elena Garro) de nuestra tragedia nacional, sin verdadera necesidad y sin ganancia científica importante.

Cerraré este trabajo con un ejemplo de investigación genética reciente que ilustra esta tendencia contemporánea. Se trata del proyecto mexicano de la llamada Genoteca Indígena dirigido por Marta Menjivar, en la UNAM, dentro del departamento de Química. En él encontramos casi sin mitigación una muestra "del viejo estilo" de la era PRIista, post-revolucionaria, de abordar paternalista y racialistamente a las poblaciones regionales y grupos étnicos. Pareciera que las décadas de disputa mundial en ética y política de la investigación en torno a la manera correcta de llevar a cabo investigación con grupos indígenas y poblaciones étnicas no hubiese tenido lugar. La mirada abiertamente colonial y paternalista es evidente y desconcertante. Las descripciones que los representantes de ese proyecto suelen dar a través de varias entrevistas, declaraciones periodísticas y conferencias, sobre todo de la investigadora principal, son peculiares (Agencia ID 2012, Fang 2015, El Universal 2013).

Se dice que se aspira a tomar muestras de por lo menos 31 grupos indígenas dentro del territorio mexicano con el objetivo de reunir una colección de muestras de sangre (que llaman genoteca indígena) para soportar la investigación genómica, para proyectos presentes y futuros. La idea es que estas muestras puedan luego ser genotipificadas de una manera más o menos densa, o de manera más particular, en búsqueda de variaciones especiales (raras) específicas relacionadas con la salud que pueden ser asociadas con patologías metabólicas. El primer objetivo es buscar variantes indígenas que predispongan a la diabetes tipo 2. Los grupos que se muestrean deben ser, según se dice, lo más puros posibles ("un alto grado de pureza"). "Pureza étnica" es un concepto que Menjívar no evita. Para no 
dejar dudas a su estilo de investigación, ella misma lo llama "Etnogenómica". Como beneficios retóricos ofrecidos en las declaraciones, se incluye una serie de ya conocidos "regalos" paternalistas para "generosos donadores indígenas", como llevar atención médica circunstancial a sitios distantes mientras que se toman las muestras, y la atención especializada para aquellos afligidos con las enfermedades metabólicas de interés. Para continuar con la retórica trasnochada, este grupo habla de la supuesta existencia de un "etnosoma" peculiar en cada grupo. Ellos intentan la descripción y catalogación a largo plazo, de éstos "etnosomas" típicos de cada grupo tipificado y tipologizado, que en su muy moderna visión incluirá complementos derivados de las nuevas ciencias "ómicas": proteómica, metabolómica, epigenómica, etc. El regusto a tipología decimonónica no se quita con esto. Además de ello, una figura retórica sin fundamento científico real utilizada por Menjívar es la otrora atractiva hipótesis del "gen ahorrador", que sostiene repetidamente que los antiguos mexicanos se adaptaron a condiciones de escasez y hambruna a través de la selección de variantes genéticos para mantenerse gordos y guardar energía dentro del cuerpo; variantes que hoy en día se han vuelto en nuestra contra de manera agresiva por los cambios dramáticos en nuestra nueva forma de vida y hábitos nutricionales. Es menester decir que no existe a estas alturas ningún antropólogo o genetista poblacional serio que piense que tal hipótesis sea verosímil. El objetivo de la investigación inicial del proyecto de la Genoteca Indígena es diagnosticar un "fondo de susceptibilidad genético" para cada grupo indígena, y para sus parientes mestizos (quienes comparten las variantes patológicas) para poder entender por qué nosotros los mexicanos somos vulnerables a sufrir de enfermedades como la diabetes, y por qué nos afecta de una manera tan distinta a como lo hace a los caucásicos, africanos y chinos (García-Deister 2014).

Las investigaciones de este grupo han empezado a ser publicadas, y en ello encontramos sobre todo asociaciones débiles entre la diabetes tipo 2 y algunas variantes genéticas que se asegura son un tanto más comunes en sus muestras amerindias (y en algunas muestras mestizas también) que en otras poblaciones mundiales. Lo cierto es que en la enorme diversidad mundial de estudios en que asocian variantes genéticas con la diabetes tipo 2, éstos del grupo de Menjívar no parecen tener una gran relevancia (Sanzhez Pozos \& Menjivar 2016, Rodríguez 2015). Otros grupos mexicanos con más experiencia de investigación, más recursos y mejores trayectorias han logrado mejores resultados en relación a variantes genéticas comunes y riesgo de padecer diabetes tipo 2 en México (Tusié 2015). Lo que hace especial al grupo que construye la llamada Genoteca Indígena es su acercamiento "etnológico" cuasi folklórico que se lleva perfectamente bien con su visión expedicionaria y redentora, y su idea romántica de la singularidad de "nuestra gente indígena hermosa" (García-Deister 2016). La manera cómo esta visión de los indígenas procede de un sentido común distorsionado, que es a su vez reforzado por la pretensión de objetividad científica de lo racial y de la inferioridad genética de lo amerindio, es preocupante. Hay cierta perversión en dirigir una vez más la culpa de los males mexicanos a los indígenas; achacar la fragilidad de los mestizos a la condición enferma de los ancestros amerindios, y explicar la enorme carga para nuestro sistema de salud, debido a la diabetes por esa herencia accidentada. Ese desvío de la culpa no es inocente, no en balde la principal institución que financia la investigación de la Genoteca Indígena ha sido durante los últimos años la Coca-Cola, un corporativo internacional de refrescos que todos conocemos. La estadística de consumo de refrescos entre mexicanos es increíble y sin duda tiene mucho más que ver con la epidemia en curso, que todos los riesgos genéticos sumados.

El hecho de que siga tan vigente el tropo de México como una nación racializada, enferma o patológica debido a su herencia genética deja bajo una luz lúgubre esta ciencia en la esfera pública. Un sentimiento de alarma y predestinación atávica domina varios debates e intercambios públicos. Los resultados de los análisis genéticos de la población se divulgan como un oráculo que es a la vez asimétrico y autoritario. En ellos la relación experto/inexperto es especialmente desequilibrada. El público (los "mestizos", los "indígenas") brindan las muestras con las que se cocinan las malas noticias "étnicas", pero también están del lado receptor de los mensajes. El tropo de la nación patológica está pues, en nuestra opinión, dañando a la gente al alterar de manera negativa su sentido de valor y 
mérito. La patologización biomédica autoritaria y vertical desplaza la responsabilidad hacia un cuerpo colectivo al condenar al portador con rasgos genéticos productores de enfermedad.

Bibliografía

Agencia ID, (2012), “Avanza UNAM en consolidación de Genoteca Indígena", Vanguardia Mx, Sección "sociedad”, 23 de agosto. Accesible en: http://www.vanguardia.com.mx/avanzaunamenconsolidaciondegenotecaindigena1358055.html (acceso 20 de junio, 2017).

Althaus, D. (2013), "How Mexico Got So Fat", Sección "Lifestyle \& Belief", Global Post, 8 de julio. Accesible en: http://www.globalpost.com/dispatch/news/regions/americas/mexico/130705/mexican-fattest-country-obesity (acceso 20 de junio, 2017).

Basave, A. (1992), México mestizo: análisis del nacionalismo mexicano en torno a la mestizofilia de Andrés Molina Enríquez, México: Fondo de Cultura Económica.

Cañizares-Esguerra, J. (1999), "New World, New Stars: Patriotic Astrology and the Invention of Indian and Creole Bodies in Colonial Spanish America, 1600-1650", The American Historical Review 104(1): 33-68.

Earle, R. (2012), The Body of the Conquistador, Cambridge: Cambridge University Press.

El Universal (2013), "Genoteca indígena recopila AND de mexicanos", Sección "Ciencia", El Universal, 31 de diciembre, 2013. Accesible en: http://archivo.eluniversal.com.mx/ciencia/2013/genoteca-indigena-adnmexicanos-82420.html (acceso 20 de junio, 2017).

Fang, J. (2015), "Mayan Ancestry Helps Explain Mexico's High Diabetes Rates", Sección "Health and medicine", IFLScience, 9 de junio. Accesible en: http://www.iflscience.com/health-and-medicine/genomes-maya-individualshelp-explain-mexicos-high-diabetes-rates/

Frenk, J. (2001), "México en el umbral de la era genómica. Impacto en la salud pública", Presentado en "México en el umbral de la era genómica", en la Ciudad de México. Accesible en: http://correo.uan.edu.mx/ indalex/ Admon/frenk.pdf (acceso 20 de junio, 2017).

Gall, O. (2013), "Mexican Long-Living Mestizophilia versus a Democracy Open to Diversity", Latin American and Caribbean Ethnic Studies. Latin American and Caribbean Ethnic Studies 8(1): 28-47.

Gamboa-Meléndez, M.A., Huerta-Chagoya, A., Moreno-Macías, H., Vázquez-Cárdenas, P., Ordóñez-Sánchez, M.L., Rodríguez-Guillén, R., Riba, L., Rodríguez-Torres, M., Guerra-García, M.T., Guillén-Pineda, L.E., Choudhry, S., del Bosque-Plata, L., Canizales-Quinteros, S., Pérez-Ortiz, G., Escobedo-Aguirre, F., Parra, A., Lerman-Garber, I., Aguilar-Salinas, C.A. y M.T. Tusié-Luna (2012), "Contribution of Common Genetic Variation to the Risk of Type 2 Diabetes in the Mexican Mestizo Population”, Diabetes 61(12): 3314-3321.

Gamio, M. (1916), Forjando patria, México: Porrúa Hermanos.

García-Deister, V. (2014), "Laboratory Life of the Mexican Mestizo", en Wade, P. (ed.), Race, Genomics and Mestizaje (mixture) in Latin America: A Comparative Approach, Durham: Duke University Press, pp. 161-182.

García-Deister, V. y C. López-Beltrán (2015), "País de gordos/país de muertos: Obesity, Death and Nation in Biomedical and Forensic Genetics in Mexico", Social Studies of Science 45(6): 797-815.

García-Deister, V. y C. López-Beltrán C. (2017), "ADN en un país de muertos. La genética forense como medio y remedio”, en Palacios, M. (coord.), Violencia y Discurso, México: UNAM, pp. 157-181.

Gerbi, A. (1955), The Dispute of the New World, Pittsburgh: University of Pittsburgh Press.

Gómez, J. y M.E. Sánchez (2011), La ideología mestizante, el guadalupanismo y sus repercusiones sociales: una revisión crítica de la 'identidad nacional', Puebla: Universidad Iberoamericana Puebla-Benemérita Universidad Autónoma de PueblaInstituto de Ciencias Sociales y Humanidades "Alfonso Vélez Pliego".

Jiménez-Sánchez, G. (2003), "La Medicina Genómica como Instrumento Estratégico en el Desarrollo de México", Ciencia y Desarrollo 29(172): 33-36. 
Jiménez-Sánchez, G. (2009), "Mapa del genoma de los mexicanos”, México: INMEGEN.

Jiménez-Sánchez, G., Soberón, G. y J. Frenk (2010), La primera década de la medicina genómica en México (1999-2009): hacia un nuevo paradigma en el cuidado de la salud. Miradas y perspectivas, México: El Colegio Nacional.

Kempis, I. (2013), “Ser médico en un país enfermo”, Sección "Reporte”, Reporte Índigo, 27 de septiembre. Accesible en: http://www.reporteindigo.com/reporte/monterrey/ser-medico-de-un-pais-enfermo (acceso 20 de junio, 2017).

Knight, A. (1990), “Racism, Revolution, and Indigenismo, Médico 1910-1940”, en Graham, R. (ed.), The Idea of Race in Latin America, 1870-1940, Austin: University of Texas Press, pp. 71-114.

Levin Rojo, D. y F. Navarrete (2007), Indios, mestizos, y españoles: interculturalidad e historiografía en la Nueva España, México: Universidad Nacional Autónoma de México.

Lisker, R. (1981), Estructura genética de la población mexicana, México: Salvat.

Lomnitz-Adler, C. (2010), "Por mi raza hablará el nacionalismo revolucionario (Arqueología de la unidad nacional)", Nexos 32(386): 42-51.

López-Beltrán, C. (2007), "Hippocratic Bodies. Temperament and Castas in Spanish America (1570-1820)”, Journal of Spanish Cultural Studies 8(2): 253-289.

López Beltrán, C. (2008), “Sangre y temperamento, pureza y mestizaje en las sociedades de castas americanas”, en Gorbach, F. y C. López Beltrán (eds.), Saberes locales: ensayos sobre historia de la ciencia en América Latina, Zamora: El Colegio de Michoacán (Debates), pp. 289-342.

López-Beltrán, C. (ed.) (2011), Genes (E) Mestizos. Genómica y Raza en la Biomedicina Mexicana, México: Ficticia-UNAM.

López-Beltrán, C. (2014), “The Matrix of the Hereditary: Race, Genetics, and Mestizo Identity”, Interdisciplina 2(4): 63. 73.

López-Beltrán, C. y V. García-Deister (en prensa), "Mestizophilia and Race Science in Early 20th Century Mexico. Special Issue on Latin Race Science", History of Science.

Rodríguez, E. (2015), "Maya Ancestry May Help Explain the High Risk of Diabetes in Mexico", Sección "News", Science, 5 de junio, 2015. Accesible en: http://www.sciencemag.org/news/2015/06/maya-ancestry-may-helpexplain-high-risk-diabetes-mexico (acceso 20 de junio, 2017).

Saade, M. (2009), El mestizo no es de color: Ciencia y política pública (México, 1920-1940), Tesis doctoral, México: Escuela Nacional de Antropologia e Historia, Instituto Nacional de Antropología e Historia.

Salzano F.M. y M.C. Bortolini (1999), The Evolution and Genetics of Latin American Populations, Cambridge: Cambridge University Press.

Sánchez-Pozos, K. y M. Menjivar (2016), "Genetic Component of Type 2 Diabetes in a Mexican Population”, Archives of Medical Research 47(7): 496-505.

SIGMA Type 2 Diabetes Consortium (2014), "Sequence Variants in SLC16A11 are a Common Risk Factor for Type 2 Diabetes in Mexico", Nature 506(7486): 97-101.

Stabb, M.S. (1967), In Quest of Identity Patterns in the Spanish American Essay of Ideas, 1890-1960, Chapel Hill: University of North Carolina Press.

Stepan, N.L. (1991), The Hour of Eugenics. Race, Gender, and Nation in Latin America, Ithaca: Cornell University Press.

Stern, A.M. (2000), "Mestizofilia, Biotipología y Eugenesia en el México Posrevolucionario: Hacia una Historia de la Ciencia y el Estado 1920-1960", Relaciones. Estudios de Historia y Sociedad 21(81): 58-91.

Stern, A. M. (2003), "Mestizophilia, Biotypology and Eugenics in Post-revolutionary Mexico: Toward a History of Science and the State, 1920-1960", en Appelbaum N.P., Macoherson, A., y K.A. Rosemblatt (eds.), Race and Nation in Modern Latin America, Chapel Hill: University of North Carolina Press, pp. 1-22.

Suárez, E. y A. Barahona (2011), "La nueva ciencia de la nación mestiza: sangre y genética humana en la posrevolución mexicana (1945-1967)”, en López Beltrán, C. (ed.), Genes (E)) Mestizos. Genómica y Raza en la Biomedicina Mexicana, México: Ficticia-UNAM, pp. 65-98.

Tenorio, M. (2006), “Guatemala y México: del mestizaje a contrapelo”, Istor (24): 67-94. 
Tenorio, M. (2009), "Del mestizaje a un siglo de Andrés Molina Enríquez", en Kourí, E. (ed.), En busca de Molina Enriquez. Cien años de los grandes problemas nacionales, México: El Colegio de México/Centro Katz, The University of Chicago, pp. 33-64.

Turda, M. y A. Gillette (2014), Latin Eugenics in Comparative Perspective, London: Bloomsbury.

Tusié, M.T. (2015), "La genómica en la predicción de la diabetes tipo 2", en Aguilar, C.A. (ed.), Acciones para enfrentar la diabetes, Mexico: Asociación Nacional de Medicina/CONACYT, pp. 145-168.

Urías Horcasitas, B. (2007a), "El hombre nuevo de la posrevolución", Letras Libres, 31 de mayo. Accesible en: http://www.letraslibres.com/mexico/el-hombre-nuevo-la-posrevolucion (acceso 26 de diciembre, 2017)

Urías Horcasitas, B. (2007b), Historias secretas del racismo en México (1920-1950), México: Tusquets.

Wade, P. (2014), Mestizo Genomics: Race Mixture, Nation, and Science in Latin America, Durham: Duke University Press. 